\title{
Preference for pasture versus freestall housing by dairy cattle when stall availability indoors is reduced
}

\author{
A. C. Falk, ${ }^{*} \dagger$ D. M. Weary, ${ }^{*}$ C. Winckler, $\dagger$ and M. A. G. von Keyserlingk ${ }^{\star 1}$ \\ *Animal Welfare Program, Faculty of Land and Food Systems, University of British Columbia, Vancouver, British Columbia, V6T 1Z4, Canada \\ †Division of Livestock Sciences, Department of Sustainable Agricultural Systems, University of Natural Resources and Life Sciences, \\ A-1180 Vienna, Austria
}

\section{ABSTRACT}

Providing cattle with access to pasture has been shown to yield benefits, including access to more space, fewer agonistic interactions, better air quality, and the ability to perform a greater range of normal behaviors. Preference for pasture appears to depend on several parameters, including weather conditions and availability of shade. The primary aim of this study was to evaluate the preference for pasture versus inside a freestall barn with variable stocking densities at the stalls. We also investigated the effect of temperature-humidity index (THI) and precipitation on this preference. Overall, cows spent on average $13.7 \pm 2.6 \mathrm{~h} / \mathrm{d}$ (mean $\pm \mathrm{SD}$ ) on pasture (ranging from 7.2 to $18.0 \mathrm{~h} / \mathrm{d}$ across days); at night (between 2000 and $0600 \mathrm{~h}$ ) cows spent the majority of their time $(78.5 \pm 27.8 \%)$ on pasture. Stall availability had no effect on time spent outside, but time spent on pasture decreased with increasing THI during the day and declined during nights with more rainfall. Stall usage changed depending on stall availability; standing with 2 and 4 feet in the stall and lying time indoors decreased with decreasing stall availability. Indoor lying time also increased with higher THI and more precipitation. In conclusion, cows preferred to be outside at night; they were much more likely to remain indoors during the day, even when overstocked. Key words: stocking density, outdoor access, animal welfare, motivation

\section{INTRODUCTION}

Access to pasture is typically considered positive for cattle welfare. In general, pasture provides cattle with more space, fewer agonistic interactions, and better air quality, and access to pasture allows the animals to perform a greater repertoire of normal behaviors such

Received November 29, 2011.

Accepted July 9, 2012.

${ }^{1}$ Corresponding author: nina@mail.ubc.ca as walking and grazing. Keeping cows on pasture is also thought to increase the frequency of affiliative behaviors and self-grooming as well as exploratory behaviors (Bartussek, 1999).

Krohn and Munksgaard (1993) reported that lying time increased when cows were housed on pasture compared with being housed in tie stalls, but other work has found that cows on pasture spend less time lying down than do cows in freestall housing (Hernandez-Mendo et al., 2007). On pasture (Phillips and Rind, 2002) and in freestall housing (DeVries et al., 2003; Fregonesi et al., 2007), cattle typically synchronize behaviors such as feeding and lying.

Cow comfort outdoors can be affected by several parameters, including weather conditions and availability of shade. Generally, cattle are more affected by heat than by cold (Hemsworth et al., 1995). The temperature-humidity index (THI) is generally used to assess thermal comfort for cattle, with a risk of thermal stress appearing at $\mathrm{THI} \geq 72$ (corresponding to $25^{\circ} \mathrm{C}$ and 50\% relative humidity; Ravagnolo et al., 2000). Thermal stress is affected by several factors, including temperature, relative humidity, solar radiation, and wind speed, and can result in decreased feed intake, milk production, and reproductive efficiency (Ravagnolo et al., 2000).

Preference tests enable animals to express their own priorities, allowing us to draw inferences regarding what is important to them (Dawkins, 1990) and how they trade-off conflicting motivations (Kirkden and Pajor, 2006). For example, previous work on indoor-housed cows has shown that cows deprived of lying will forgo opportunities to feed in order to lie down (Munksgaard et al., 2005). When provided a choice between pasture and indoor housing, cows showed a partial preference to be outdoors (Legrand et al., 2009; Charlton et al., 2011a,b); cow preferences appear to be associated with nutritional demands (Charlton et al., 2011b), time of day, and environmental factors (Legrand et al., 2009). During the summer months, when the latter study took place, cattle preferred to access pasture at night and were more likely to remain inside the freestall barn dur- 
ing the day, especially when temperatures were higher (Legrand et al., 2009).

Overstocking at the stalls (i.e., insufficient lying places for the number of cows) reduced lying time, increased the time spent standing in the alleys, and increased the number of displacements from the stalls in mid-lactation cows (Fregonesi et al., 2007). With decreasing availability of stalls, cows also had shorter latency to lie down after milking in an apparent attempt to secure a lying position, most likely at the expense of feeding time after milking (Fregonesi et al., 2007). Similar effects on lying and standing in the alleys have been reported when stocking density was increased in both stalls and headlocks (Krawczel et al., 2008; Hill et al., 2009).

Previous work on preference and usage of pasture versus freestall indoor housing (Legrand et al., 2009) has not explored how modifying the conditions in the barn affects pasture preference. Therefore, the primary aim of the current study was to evaluate the preference for pasture by varying the number of lying places (freestalls) available inside the barn. The secondary objective was to determine how diurnal and environmental factors affected this preference. We predicted that cows would reduce the time spent indoors when stall availability decreased. We also predicted that use of indoor housing would increase with higher THI and precipitation, and decrease at night.

\section{MATERIALS AND METHODS}

\section{Cows and Treatment}

This experiment took place at The University of British Columbia's Dairy Education and Research Centre (Agassiz, BC, Canada) between June and September 2010. Cattle were cared for according to the Canadian Council on Animal Care Guidelines for Farm Animals (CCAC, 2009). We used 3 groups of 24 lactating Holstein dairy cows averaging $( \pm \mathrm{SD}) 276 \pm 72.6 \mathrm{DIM}, 2.2$ \pm 1.4 lactations, $23 \pm 4 \mathrm{~kg} / \mathrm{d}$ of milk production, 673 $\pm 85 \mathrm{~kg}$ of BW, and $3.4 \pm 0.3 \mathrm{BCS}$, scored following Ferguson et al. (1994). Groups did not differ in any of these parameters. Cows showed no signs of illness or lameness during the study.

All cows had previous experience with pasture and freestall housing. To reinforce this prior experience, each group was familiarized with both housing conditions during a 6-d adaptation phase before the experiment started. During the adaptation phase, cows were confined to pasture except for $2 \mathrm{~h}$ after each milking, when they were given access to a TMR, with each cow provided $60 \mathrm{~cm}$ of feed bunk space. After the adaptation phase, cows had free access to pasture and the freestall barn. Stall availability $(0,8,16$, or 24 stalls per group of 24 cows) inside the barn was varied daily, with treatment order pseudo-randomized such that each group was tested on each treatment on 4 separate days, resulting in a total of 16 experimental days per group. Each treatment condition was tested over 4 separate days so as to provide a range of climatic conditions.

\section{Housing, Management, and Feed Intake}

All groups were housed in the same freestall pen (width $=12.2 \mathrm{~m}$ and length $=19.5 \mathrm{~m}$ ) with 24 freestalls configured in 2 rows. The alley between the 2 rows was $3.0 \mathrm{~m}$ wide. Each stall had a geotextile mattress covered with washed river sand $(0.1 \mathrm{~m}$ depth $)$ and was 1.2 $\mathrm{m}$ wide and $2.7 \mathrm{~m}$ long. Individual stalls were separated by a freestall divider (Artex, Langley, BC, Canada) and fitted with a brisket board that was located $1.7 \mathrm{~m}$ from the internal side of the curb (0.2 $\mathrm{m}$ high). During treatments in which stall availability was reduced, consecutive stalls were blocked using chains to prevent entry.

Flooring throughout the pen was composite rubber (including the crossover alleys). The alleys were automatically scraped 5 times a day, and crossover alleys were manually scraped twice a day. The experimental pen was fitted with head lockers (see description in Huzzey et al., 2006) and 2 self-filling water troughs (see description in Chapinal et al., 2007). A TMR containing $36.8 \%$ corn silage, $16.7 \%$ grass silage, $15.8 \%$ alfalfa hay, $2.7 \%$ straw, and $28.0 \%$ grain (\% of DM basis) was provided ad libitum.

Fresh TMR samples were taken twice weekly (every Monday and Thursday at approximately 0745 h) immediately before feed delivery. Samples were pooled to create one representative sample for each replication. Samples were dried at $60^{\circ} \mathrm{C}$ for $48 \mathrm{~h}$ to determine DM content and then ground and sent for nutritional analysis at Cumberland Valley Analytical Service (Hagerstown, MD). The TMR contained (averaged from 3 samples) $48.3 \pm 1.6 \% \mathrm{DM}$ and (on a DM basis) 14.5 $\pm 0.4 \% \mathrm{CP}, 39.4 \pm 8.0 \% \mathrm{NDF}$, and $33.5 \pm 9.0 \% \mathrm{ADF}$.

The entrance to the pasture was approximately $15 \mathrm{~m}$ from the barn. An electric fence was used to divide the pasture into 3 plots ( $30 \mathrm{~m}$ wide $\times 120 \mathrm{~m}$ long) to ensure that cows had access to fresh pasture each day. Every morning, while the cows were being milked, the fencing was moved to increase the size of the plot by approximately $10 \mathrm{~m}$ in length. The pasture was a mixture of 50:50 Dactylis glomerata (orchardgrass) and Festuca arundinacea (tall fescue), which had been newly seeded in the previous year. No natural or artificial shade was provided on the pasture.

Pasture samples were taken twice weekly (every Monday and Thursday at $1600 \mathrm{~h}$ ) in the $10-\mathrm{m}$ section 
allocated for grazing the following morning. Samples were pooled after each replicate to create one representative sample. Samples were dried at $60^{\circ} \mathrm{C}$ for $48 \mathrm{~h}$ to determine DM content. Dried samples were pooled, ground, and sent for nutritional analysis (Cumberland Valley Analytical Service,). Pasture averaged (across the 3 samples) $20.1 \pm 3.9 \% \mathrm{DM}$ and (expressed as $\%$ of DM) $19.4 \pm 1.6 \% \mathrm{CP}, 60.8 \pm 2.4 \% \mathrm{NDF}$, and 32.4 $\pm 1.9 \% \mathrm{ADF}$.

\section{Behavioral Measures}

Five Panasonic CCTV cameras (model WV, BP 314 Matsushita Communication Industrial Corporation of the Philippines, Panasonic System Solutions, Suzhou, China) were used to monitor the behavior of the cows in the barn. Two cameras were located $5 \mathrm{~m}$ above the feeding area and 2 above the lying area. One camera (Panasonic WV-CW504SP; 0.1 lx low-light sensitive) was used to monitor cows leaving and returning from pasture. Cameras were connected to a digital video recorder (GV1480-32 HV3, USA Vision Systems Inc., Irvine, CA). Red lights (wavelength approximately 650 $\mathrm{nm}$ ) were placed adjacent to each camera to facilitate cow identification at night $(\sim 2300 \mathrm{~h}$ to $0500 \mathrm{~h})$. Individual cows were identified by a unique symbol placed on the back of each cow using hair dye.

Lying times and number of lying bouts were recorded using Hobo data loggers (Pendant G Acceleration Data Logger, Onset Computer Corp., Pocasset, MA) attached to the rear leg of each cow. These loggers were set to record the acceleration in the vertical and horizontal axes of the cow's rear leg at 1-min intervals (Ledgerwood et al., 2010). Loggers were attached and removed in the milking parlor once a week to allow data transfer.

Behavior of the cows while indoors was recorded from the video using instantaneous scan sampling at 5-min intervals, providing 288 scans for each day of observation. Cows were recorded as lying in the stall, lying in the alleyways or passages between alleyways, lying in the entrance way leading to the pasture on concrete, standing with the front 2 feet in the stall, standing with 4 feet in the stall, standing in the alley, or feeding (i.e., with the head over the feed bunk). These behaviors were not scored while cows were out of the pen for milking, for approximately $30 \mathrm{~min}$ twice daily (i.e., duration from the time they were moved to the milking parlor until they were returned to the pen).

\section{Climatic Measures}

Hourly air temperature $\left({ }^{\circ} \mathrm{C}\right)$, relative humidity $(\%)$, and wind speed $(\mathrm{km} / \mathrm{h})$, and daily precipitation (mm) were downloaded from the Environment Canada weather station located approximately $400 \mathrm{~m}$ from UBC Dairy Education and Research Centre. Hourly air temperature and humidity measures were collected using a Hobo U23 Pro v2 Temperature/Relative Humidity Data Logger (Onset Computer Corp.) positioned 3 $\mathrm{m}$ above the ground in the middle of the freestall pen. Temperature-humidity index was calculated following Ravagnolo et al. $(2000): \mathrm{THI}=(1.8 \mathrm{~T}+32) \times[(0.55-$ $0.0055 \mathrm{RH}) \times(1.8 \mathrm{~T}-26)]$, where $\mathrm{T}=$ air temperature $\left({ }^{\circ} \mathrm{C}\right)$ and $\mathrm{RH}=$ relative humidity $(\%)$.

\section{Statistical Analyses}

Data from loggers were summarized to calculate mean lying time and number of lying bouts. Time on pasture (i.e., outside the barn), lying time in the stalls, lying time in the alleys or exit areas, time standing in the alley, time standing with 2 and 4 feet in the stall, and time feeding in the barn were calculated from scan sampling data. Lying time on pasture was calculated by subtracting lying time in the barn (from scan sampling) from total lying time as assessed using the Hobo data loggers. Data were separated into day (0835 to 1500 h; daylight hours between morning and evening milkings) and night (2000 to $0600 \mathrm{~h}$; between dusk and morning milking) periods and averaged to create one value per group $(\mathrm{n}=3)$, day $(\mathrm{n}=16)$, and period (day and night).

These data were analyzed using PROC MIXED in SAS (version 9.2, SAS Institute Inc., Cary, NC), separately for day and night periods, with treatment and climate variables as continuous fixed effects and group specified as a random effect, using an autoregressive co-variance structure.

\section{RESULTS}

Cows spent, on average, $13.7 \pm 2.8 \mathrm{~h} / \mathrm{d}$ on pasture (mean $\pm \mathrm{SD}$ ), but this ranged from 7.2 to $18.0 \mathrm{~h} / \mathrm{d}$ across days. Use of pasture varied with time of day; cows spent more time outside at night (averaging 78.5 $\pm 27.8 \%$ of their time on pasture between 2000 and $0600 \mathrm{~h}$ ) than they did during the day (averaging 41.5 $\pm 39.8 \%$ of the time on pasture between 0835 and 1500 h). On average, cows consumed $15.4 \pm 2.4 \mathrm{~kg}$ of DM/d of the TMR while indoors.

The daily temperature averaged $17.0 \pm 4.3^{\circ} \mathrm{C}$ (mean $\pm \mathrm{SD}$ ) outside the barn and ranged from 9 to $29.6^{\circ} \mathrm{C}$. Temperature inside the barn averaged $18.6 \pm 4.3^{\circ} \mathrm{C}$, ranging from 9.7 to $30.4^{\circ} \mathrm{C}$. Precipitation averaged 3 $\pm 6 \mathrm{~mm} / \mathrm{d}$, ranging from 0 to $25 \mathrm{~mm} / \mathrm{d}$. Wind speed averaged $5.5 \pm 4.2 \mathrm{~km} / \mathrm{h}$, with a range from 0 to 28 $\mathrm{km} / \mathrm{h}$. Relative humidity averaged $78.4 \pm 16.1 \%$ and 


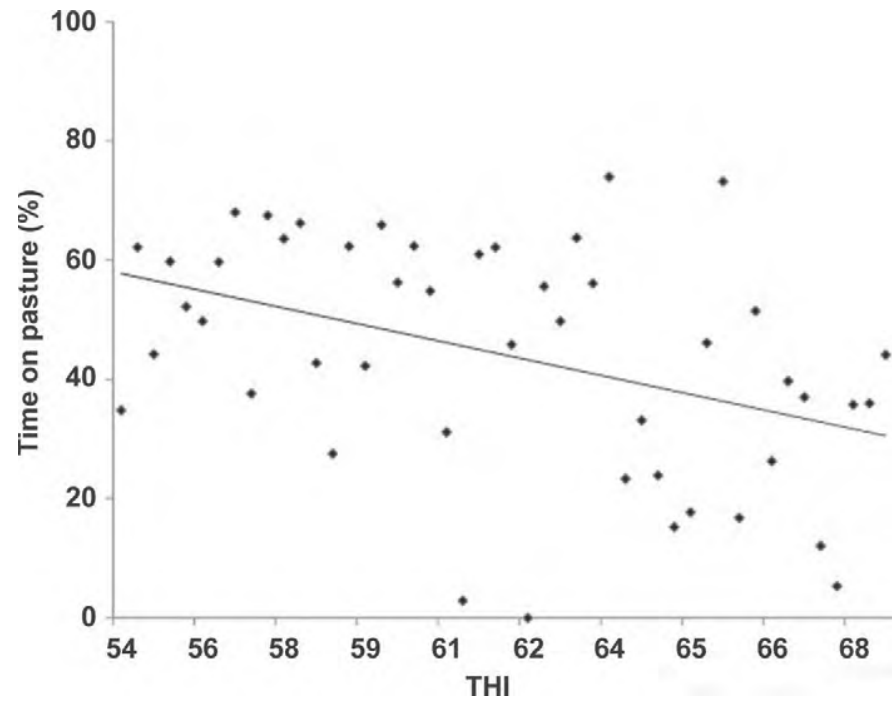

Figure 1. Mean percentage of time cows spent outside on pasture when provided free access to pasture and freestall housing. Data are shown in relation to the average temperature-humidity index (THI) for the daytime period $(0835$ to $1500 \mathrm{~h})$ for each day $(\mathrm{n}=48)$ of the trial.

$71.2 \pm 12.2 \%$ outside and inside the barn, respectively. Climatic variables inside and outside were highly correlated (i.e., correlation coefficient of outside and inside THI $=0.97)$, so only the outside values were used in the analysis presented below.

Stall availability had no effect on the time spent outside, but time spent on pasture decreased with increasing THI during the day (Figure $1 ; \mathrm{F}_{1.41}=5.29 ; P$ $=0.03$ ) and declined during nights with more rainfall (slope $=-1.3 \pm 0.5 \%$ time outside $/ \mathrm{mm}$ of precipitation; $\left.\mathrm{F}_{1,41}=8.09 ; P=0.007\right)$.

Total lying time and lying outside on pasture were not influenced by stall availability (Figure 2) but the latter decreased with precipitation (slope $=-1.1 \pm$ $0.49 \%$ time outside $/ \mathrm{mm}$ of precipitation; $\mathrm{F}_{1,41}=5.11$; $P=0.029$ ). Lying time inside (i.e., in the stalls) decreased with decreasing stall availability (Figure 2; $\mathrm{F}_{1,41}$ $=52.69 ; P<0.0001$ ) and increased with THI (slope $=$ $0.5 \pm 0.24 \%$ time outside/THI; $\mathrm{F}_{1,41}=4.77 ; P=0.03$ ) and precipitation (slope $=0.5 \pm 0.16 \%$ time outside/ $\mathrm{mm}$ of precipitation; $\left.\mathrm{F}_{1.41}=8.73 ; P=0.005\right)$. Lying events where cows elected to lie down in the alleys occurred infrequently ( $0.4 \%$ of the lying events; 10 different cows), and cows did not lie down in the alley when stall availability was not limiting.

The time cows spent standing inside the barn in the alley increased with decreasing stall availability $\left(\mathrm{F}_{1,41}\right.$ $=16.87 ; P=0.0002)$. Time spent standing in the stall with 4 feet $\left(\mathrm{F}_{1,41}=18.29 ; P=0.0001\right)$ or 2 feet in the stall $\left(\mathrm{F}_{1.41}=53.43 ; P<0.0001\right)$ decreased with decreasing stall availability (Table 1 ).

\section{DISCUSSION}

Cows averaged $42 \%$ of their time indoors, with the majority of this time taking place during the day. This finding is similar to the results reported by Legrand et al. (2009), where cows spent, on average, $46 \%$ of their time indoors. Charlton et al. (2011a) reported a stronger preference for indoor housing, with cows
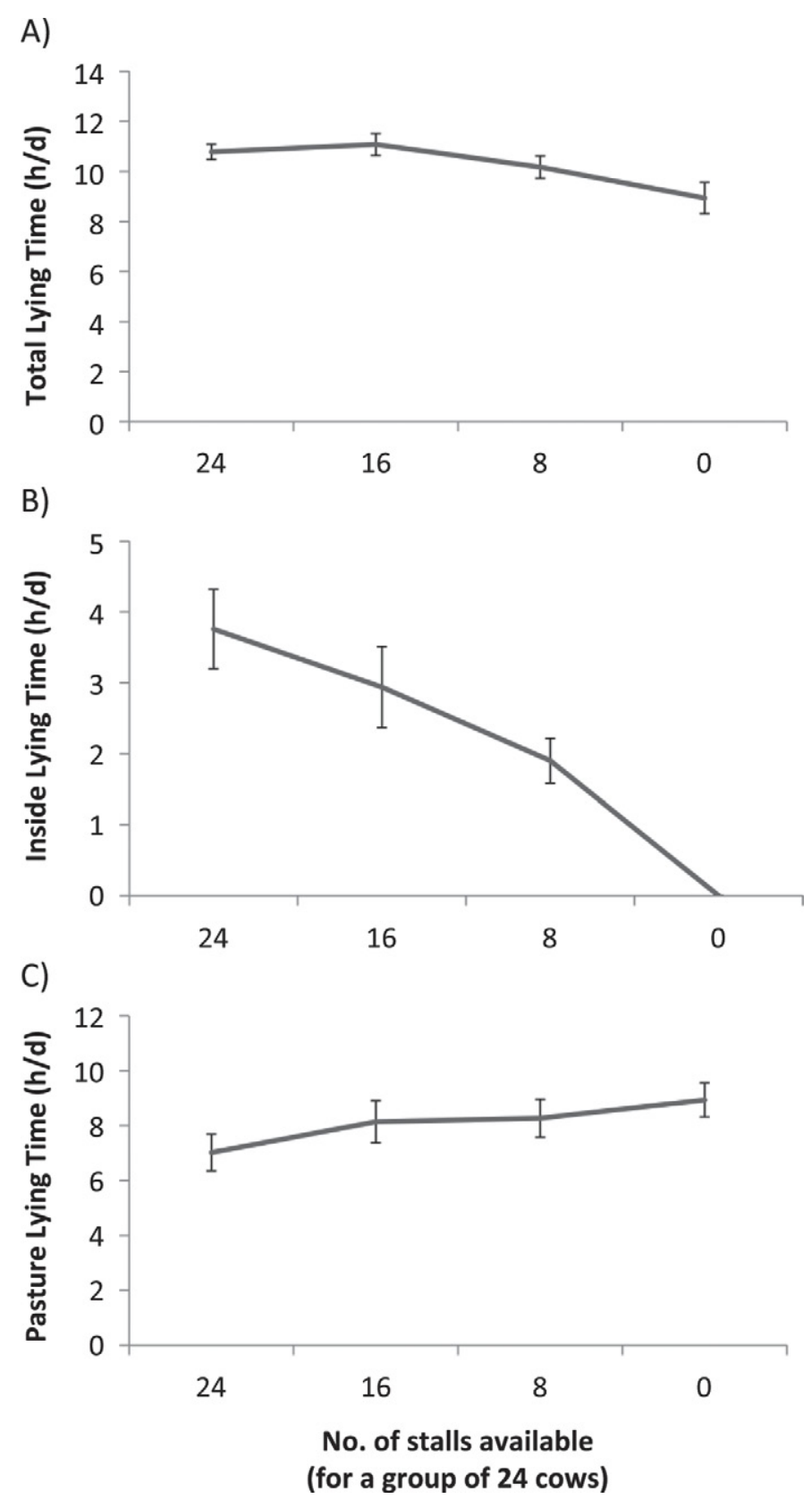

Figure 2. Mean time $( \pm \mathrm{SE} ; \mathrm{h} / \mathrm{d})$ cows spent lying down $\mathrm{A})$ in total, B) inside the freestall barn, and C) outside on pasture when provided free access to both housing conditions (mean of 3 groups, each of 24 cows). Results are shown separately by treatment (i.e., 24, 16, 8, or 0 stalls available inside the barn). 
Table 1. Mean $( \pm \mathrm{SE})$ time cows spent standing (h/cow per day) inside the barn in the alley, in the stall with 4 feet, and in the stall with 2 feet when there was free access to pasture in relation to the number of stalls available inside the barn per group of 24 cows

\begin{tabular}{lcccccrrr}
\hline & \multicolumn{4}{c}{ Number of stalls available } & & \\
\cline { 2 - 6 } Behavior & 24 & 16 & 8 & 0 & F & $P$-value & SE \\
\hline Standing in the alley & 1.68 & 1.64 & 2.29 & 3.80 & 16.9 & 0.0002 \\
Standing in stall with 4 feet & 0.03 & 0.02 & 0.01 & - & 18.3 & 0.007 \\
Standing in stall with 2 feet & 0.43 & 0.40 & 0.27 & 0.04 & 53.4 & $<0.0001$ & 0.001 \\
\hline
\end{tabular}

spending about $90 \%$ of their time inside when a TMR was only provided in the barn. In a subsequent study with provision of TMR both indoors and on pasture, Charlton et al. (2011b) found that cows spent just $29 \%$ of their time indoors, but this partial preference for pasture was not affected by the provision of TMR. The unusually low amount of pasture use in the Charlton et al. (2011a) study was likely related to the cows' lack of previous experience with pasture and long walking distances between the barn and the pasture. All cows in the current study had previous experience on pasture, but all had also been confined indoors during the previous winter. We provided cows a 6 -d habituation period to adapt to pasture before data collection began but some cows may still have found the pasture unfamiliar. Future work in this area should investigate the effects of longer periods of adaptation on the preference of pasture by dairy cattle. In the current experiment, cows were not habituated to the various overstocking levels; it is also possible that the effects of overstocking would have been stronger if cows had been tested over longer periods at each level.

In agreement with the results reported by Legrand et al. (2009), cows in the present study spent about $57 \%$ of their time on pasture, with the majority of this occurring at night. In contrast, cows spent the majority of the day indoors, regardless of stall availability. The preference for pasture at night, when cows typically spend most of their time lying down, may reflect a desire to lie down on pasture versus in the freestalls. Fregonesi et al. (2009) reported that cows preferred to lie down in an open-pack versus freestalls, so it is possible that the preference for pasture at night is related to the unconstrained lying surface available on pasture. For instance, the opportunity to freely select a lying place and distance to a nearest neighbor, and the absence of any mechanical barriers such as partitions between stalls, neck rails, or brisket boards, may have individually or collectively contributed to the preference for the use of the pasture at night.

Generally, time budgets of cows are affected by environmental conditions such as solar radiation (Tucker et al., 2008), temperature (Hemsworth et al., 1995), THI (West, 2003; Legrand et al., 2009), and precipita- tion (Vandenheede et al., 1995; Legrand et al., 2009; Charlton et al., 2011a,b). Legrand et al. (2009) found a relationship between THI and precipitation and time spent indoors; cows preferred to be indoors during the day, especially at higher temperatures and during periods of rain, and preferred the outdoor environment during the night. We noted similar relationships, with cows moving indoors when THI or rainfall was high. Heat load index (HLI), incorporating black globe temperature, relative humidity, and wind speed better accounts for cumulative effects of heat load than does THI (Gaughan et al., 2008). These effects may be especially important for pasture-based systems, where the animals are exposed to direct solar radiation. However, under moderate summer conditions as in the current study, THI and HLI have similar effects on time budgets of dairy cows (Legrand et al., 2011). Weather conditions in the current study did allow for heat dissipation during the night, making cumulative effects of heat load less likely. Nevertheless, we suggest the use of the HLI in future work.

Daily lying times indoors decreased with decreasing stall availability but total lying time was not significantly reduced. Other work on overstocking (e.g., Friend et al., 1977; Fregonesi et al., 2007; Krawczel et al., 2008; Hill et al., 2009) showed reduced lying times for dairy cattle housed indoors when stall availability was reduced and the cows were not able to switch to an alternative resting place. In the present study, cows compensated slightly for the reduced time spent lying indoors by increasing the amount of time lying on pasture. We suggest that increases in lying time outside were limited, however, by a ceiling effect; cows spent the large majority of their time outside lying down even when there was no competition for stalls, reducing the scope for increased lying times outdoors when stall availability indoors was limited.

Reduced lying time indoors was also accompanied by an increase in the number of cows standing in the alley when fewer stalls were available. The time spent standing fully or partially in the stall also decreased with overstocking. These results correspond with those of Fregonesi et al. (2007), who reported that overstocked cows spent more time standing outside the freestalls. 
Cows reduced time spent lying on pasture when it was raining, especially at night; this result is consistent with earlier work on pastured cows showing an increase in the number of animals seeking shelter during periods of rainfall (Vandenheede et al., 1995). During periods of heavy rainfall, the lying surface outside was wet and muddy in some locations; Fisher et al. (2003) reported decreases in lying time when cows on pasture were not provided well-drained and comfortable lying surfaces. Work on cows housed indoors also reported reductions in lying times when the lying surface was wet (Fregonesi et al., 2009; Reich et al., 2010). Other work has investigated the effects of milk yield, BCS, and stage of lactation on the time spent lying by indoor-housed cows; the results of this work indicate that lying time increases with DIM (Bewley et al., 2010), likely because feed intake and time spent eating decrease following peak lactation.

During the day, when most cows preferred to be indoors, a few cows elected to lie down in the alley or crossover alley when stall availability was limited. This observation may suggest that cows sometimes choose to lie down in a nonpreferred location (the alley) rather than go outside alone. Future work should consider the effect of a cow's motivation to leave and return from pasture relative to motivation to be with group mates.

\section{CONCLUSIONS}

Similar to previous work, cows in the current study showed a partial preference for pasture at night and for freestall housing (with access to TMR) during the day. Use of pasture was also influenced by temperature and rainfall. Availability of freestalls indoors did not change the proportion of time that cows spent on pasture, suggesting that cows viewed indoor housing more as a place to feed and escape outdoor environmental conditions than as a place to lie down.

\section{ACKNOWLEDGMENTS}

We thank the faculty, staff, and students at the University of British Columbia's Dairy Education and Research Centre and the University's Animal Welfare Program. M. A. G. von Keyserlingk and D. M. Weary are supported by Canada's Natural Sciences and Engineering Research Council (NSERC) Discovery program and the NSERC Industrial Research Chair Program with industry contributions from the Dairy Farmers of Canada (Ottawa, ON, Canada), Westgen Endowment Fund (Milner, BC, Canada), Pfizer Animal Health (Kirkland, QC, Canada), BC Cattle Industry Development Fund (Kamloops, BC, Canada), the BC Milk
Producers (Burnaby, BC, Canada), BC Dairy Foundation (Burnaby, BC, Canada), BC Dairy Education and Research Association (Abbotsford, BC, Canada), and Alberta Milk (Edmonton, AB, Canada).

\section{REFERENCES}

Bartussek, H. 1999. A review of the animal needs index (ANI) for the assessment of animals' well-being in the housing systems for Austrian proprietary products and legislation. Livest. Prod. Sci. 61:179-192.

Bewley, J. M., R. E. Boyce, J. Hockin, L. Munksgaard, S. D. Eicher, M. E. Einstein, and M. M. Schutz. 2010. Influence of milk yield, stage of lactation, and body condition on dairy cattle lying behavior measured using an automated activity monitoring sensor. J. Dairy Res. 77:1-6.

CCAC. 2009. Guidelines on: The care and use of farm animals in research, teaching and testing. Canadian Council on Animal Care, Ottawa ON, Canada.

Chapinal, N., D. M. Veira, D. M. Weary, and M. A. G. von Keyserlingk. 2007. Technical note: Validation of a system for monitoring individual feeding and drinking behavior and intake in grouphoused dairy cattle. J. Dairy Sci. 990:5732-5736.

Charlton, G. L., S. M. Rutter, M. East, and L. A. Sinclair. 2011a. Preference of dairy cows: Indoor cubicle housing with access to a total mixed ration vs. access to pasture. Appl. Anim. Behav. Sci. 130:1-9.

Charlton, G. L., S. M. Rutter, M. East, and L. A. Sinclair. 2011b. Effects of providing total mixed rations indoors and on pasture on the behavior of lactating dairy cattle and their preference to be indoors or on pasture. J. Dairy Sci. 94:3875-3884.

Dawkins, M. S. 1990. From an animal's point of view: Motivation, fitness, and animal welfare. Behav. Brain Sci. 13:1-61.

DeVries, T. J., M. A. G. von Keyserlingk, and K. A. Beauchemin. 2003. Diurnal feeding pattern of lactating dairy cows. J. Dairy Sci. 86:4079-4082.

Ferguson, J. D., D. T. Galligan, and N. Thomsen. 1994. Principal descriptors of body condition score in Holstein cows. J. Dairy Sci. 77:2695-2703.

Fisher, A. D., M. Stewart, G. A. Verkerk, C. J. Morrow, and L. R. Matthews. 2003. The effects of surface type on lying behavior and stress responses of dairy cows during periodic weather-induced removal from pasture. Appl. Anim. Behav. Sci. 81:1-11.

Fregonesi, J. A., C. B. Tucker, and D. M. Weary. 2007. Overstocking reduces lying time in dairy cows. J. Dairy Sci. 90:3349-3354.

Fregonesi, J. A., M. A. G. von Keyserlingk, and D. M. Weary. 2009. Cow preference and usage of free stalls compared with an open pack area. J. Dairy Sci. 92:5497-5502.

Friend, T. H., C. E. Polan, and M. L. McGilliard. 1977. Free stall and feed bunk requirements relative to behavior, production and individual feed intake in dairy cows. J. Dairy Sci. 60:108-116.

Gaughan, J. B., T. L. Mader, S. M. Holt, and A. Lisle. 2008. A new heat load index for feedlot cattle. J. Anim. Sci. 86:226-234.

Hemsworth, P. H., J. L. Barnett, L. Beveridge, and L. R. Matthews. 1995. The welfare of extensively managed dairy cattle: A review. Appl. Anim. Behav. Sci. 42:161-182.

Hernandez-Mendo, O., M. A. G. von Keyserlingk, D. M. Veira, and D. M. Weary. 2007. Effects of pasture on lameness in dairy cows. J. Dairy Sci. 90:1209-1214.

Hill, C. T., P. D. Krawczel, H. M. Dann, C. S. Ballard, R. C. Hovey, W. A. Falls, and R. J. Grant. 2009. Effect of stocking density on the short-term behavioural responses of dairy cows. Appl. Anim. Behav. Sci. 117:144-149.

Huzzey, J. M., T. J. DeVries, P. Valois, and M. A. G. Von Keyserlingk. 2006. Stocking density and feed barrier design affect the feeding and social behavior of dairy cattle. J. Dairy Sci. 89:126-133.

Kirkden, R. D., and E. A. Pajor. 2006. Using preference, motivation and aversion tests to ask scientific questions about animals' feelings. Appl. Anim. Behav. Sci. 100:29-47. 
Krawczel, P. D., C. T. Hill, H. M. Dann, and R. J. Grant. 2008. Effect of stocking density on indices of cow comfort. J. Dairy Sci. 91:1903-1907.

Krohn, C. C., and L. Munksgaard. 1993. Behaviour of dairy cows kept in extensive (loose housing/pasture) or intensive (tie stall) environments: II. Lying and lying-down behavior. Appl. Anim. Behav. Sci. 37:1-16.

Ledgerwood, D. N., C. Winckler, and C. B. Tucker. 2010. Evaluation of data loggers, sampling intervals, and editing techniques for measuring the lying behavior of dairy cattle. J. Dairy Sci. 93:5129-5139.

Legrand, A., K. E. Schütz, and C. B. Tucker. 2011. Using water to cool cattle: Behavioral and physiological changes associated with voluntary use of cow showers. J. Dairy Sci. 94:3376-3386.

Legrand, A. L., M. A. G. von Keyserlingk, and D. M. Weary. 2009. Preference and usage of pasture versus free-stall housing by lactating dairy cattle. J. Dairy Sci. 92:3651-3658.

Munksgaard, L., M. B. Jensen, L. J. Pedersen, S. W. Hansen, and L. Matthews. 2005. Quantifying behavioural priorities-Effects of time constraints on behavior of dairy cows. Appl. Anim. Behav. Sci. $92: 3-14$.
Phillips, C. J. C., and M. I. Rind. 2002. The effects of social dominance on the production and behavior of grazing dairy cows offered forage supplements. J. Dairy Sci. 85:51-59.

Ravagnolo, O.. I. Misztal, and G. Hoogenboom. 2000. Genetic component of heat stress in dairy cattle, development of heat index function. J. Dairy Sci. 83:2120-2125.

Reich, L. J., D. M. Weary, and M. A. G. von Keyserlingk. 2010. Effects of sawdust bedding dry matter on lying behavior of dairy cows: A dose dependent response. J. Dairy Sci. 93:1561-1565.

Tucker, C. B., A. R. Rogers, and K. E. Schutz. 2008. Effect of solar radiation on dairy cattle behavior, use of shade and body temperature in a pasture-based system. Appl. Anim. Behav. Sci. 109:141-154.

Vandenheede, M., B. Nicks, R. Shehi, B. Canart, I. Dufrasne, R. Biston, and P. Lecomte. 1995. Use of a shelter by fattening bulls: Effect of climatic factors. Anim. Sci. 60:81-85.

West, J. W. 2003. Effects of heat stress on production in cattle. J. Dairy Sci. 86:2131-2144. 